\title{
O AGRONEGÓCIO DA ÁGUA
}

\author{
Tamara Esteves de Oliveira* \\ David Santos de Freitas** \\ Luis Henrique Ramos Camfield ${ }^{* * *}$ \\ Matheus Dhein Dill ${ }^{* * * *}$
}

RESUMO: A produção agrícola é uma das atividades que mais demanda água sendo necessária uma visão estratégica dos recursos hídricos, de forma que se mantenha a produtividade, sem comprometer a sustentabilidade hídrica desses sistemas. As novas tecnologias e a gestão de recursos naturais surgem para evitar desperdícios e adequar sua utilização. Frente a esta problemática, este artigo busca esclarecer os conceitos referentes à água e seu agronegócio, propondo uma visão ampla da questão e tentando aproximá-la do agronegócio brasileiro. Assim, é possível observar que em todos os produtos comercializados, desde alimentos, peças de vestuário e aparelhos eletrônicos, existe um consumo de água que não é demonstrado ao consumidor na embalagem, omitindo o verdadeiro impacto hídrico daquele produto. A pegada hídrica e terminologias, como a água virtual, são ferramentas que contribuem para amenizar problemas de escassez de água em diferentes regiões do mundo por meio do comércio internacional. Devido à característica cíclica da água, esse recurso sofre uma redução de sua disponibilidade utilizável frente a uma população crescente que carece de uma gestão adequada. Caso não sejam aprofundadas e aplicadas as ferramentas aqui dispostas pode não ser possível manter as condições de bem-estar e segurança que a sociedade tem almejado.

PALVRAS-CHAVE: Desenvolvimento sustentável; Pegada hídrica; Produção de alimentos; Recursos naturais.

\footnotetext{
Doutoranda pelo Centro de Estudos e Pesquisas em Agronegócios pela Universidade Federal do Rio Grande do Sul (UFRGS), Brasil.

** Doutorando do Programa de Pós-graduação em Biologia na Universidade do Vale do Rio dos Sinos (UNISINOS), São Leopoldo, Brasil; E-mail: davids.freitas@yahoo.com.br

${ }^{* * *}$ Doutorando pelo Centro de Estudos e Pesquisas em Agronegócios pela Universidade Federal do Rio Grande do Sul (UFRGS), Brasil.

**** Pós Doutorando pelo Centro de Estudos e Pesquisas em Agronegócios pela Universidade Federal do Rio Grande do Sul (UFRGS), Brasil.
} 


\section{WATER AGRIBUSINESS}

ABSTRACT: Agriculture is one of the activities that most requires water. A strategic foresight for water resources is required for the maintenance of productivity without jeopardizing the systems' water sustainability. New technologies and the management of natural resources are thus adopted to avoid wastes and adequate their use. Current paper analyzes the concepts on water and agribusiness, and thus proposes a wide survey of the issue, forwarding it close to Brazilian agribusiness. It should be underscored that in all commercialized products, from food, clothes and electronic equipments, certain water consumption exists which labels fail to exhibit and thus the real water impact of the product is omitted. Water footprint and terminology, such as virtual water, are tools that contribute towards the lessening of problems of water scarcity in different regions of the planet through international trade. Due to the water's cyclical characteristics, there is a reduction in its availability because of a growing population that lacks adequate management. If these tools are not deepened and applied, the welfare and safety conditions that society desires will not be maintained.

KEY WORDS: Sustainable development; Water footprint; Food production; Natural recourses.

\section{INTRODUÇÃO}

A produção agrícola demanda grande quantidade de água, sendo a eficiência desta utilização relevante para a produtividade desta atividade. A tecnologia e a gestão de recursos hídricos podem contribuir para evitar desperdícios e a utilização inadequada deste patrimônio fundamental.

Algumas propostas surgem nessa busca por gerenciar os recursos hídricos utilizados na produção. Dentre elas, o conceito de pegada hídrica, que surgiu no início dos anos 2000; seguindo a mesma linha de duas outras pegadas: a ecológica, que mede em hectares quanto uma pessoa/população necessita para produzir os recursos que consome; e a de carbono, que mede a quantidade de gás carbônico produzida pelas pessoas durante sua vida.

Outra abordagem interessante se refere às formas de valorização, comercialização e negociação da água, seja como produto ou como bem público. 
Dentro desta concepção surge a proposta de água virtual e outras formas de receber valor financeiro por este recurso natural. Os diversos enfoques dados ao tema refletem sua complexidade e importância, pois a partir do estudo das possibilidades de uso e consumo da água, será possível propor formas de aproveitamento dos benefícios desse recurso essencial. Entretanto, para compreender as nuances desta questão é necessário abranger diversas áreas do conhecimento, reconhecendo a importância de questões ambientais e o impacto da comercialização da água.

A partir da análise destas questões e do consumo e abastecimento hídrico existem diversas questões a serem consideradas que podem auxiliar no correto gerenciamento da água. Frente a esta problemática, este artigo busca esclarecer os conceitos ligados ao agronegócio da água, propondo uma visão ampla da questão e tentando aproximá-la do agronegócio brasileiro.

\section{A QUESTÃo ÁGUA}

Por muito tempo a água foi considerada um recurso natural infinito, com pouco ou nenhum valor econômico, tendo em seu uso indiscriminado um dos principais motivos geradores da redução em sua oferta (HESPANHOL; MIERZWA, 2000). Apesar do grande volume de água existente no planeta Terra, apenas $2,8 \%$ são adequados para o consumo humano, sendo que 2,2\% encontram-se em geleiras e apenas 0,6\% em rios, lagos e lençóis subterrâneos (COÊLHO, 2001).

Este conflito envolve também o direito à água e sua relação com a saúde, visto que a falta de saneamento básico, além de proliferar inúmeras doenças, aumentando a mortalidade infantil, principalmente entre as camadas sociais menos favorecidas, é fator imprescindível para manter o bem-estar e a higiene humana (IRIGARAY, 2004).

Segundo a Organização das Nações Unidas (ONU), mais de 70\% da população mundial não dispõe de água potável (ONU, 1997). Esta disponibilidade está relacionada diretamente à questão da saúde pública, onde a falta de abastecimento de água potável contribui para doenças e mortes nos países em desenvolvimento.

O privilégio do Brasil nessa questão é o fato de possuir 14\% da água doce que circula sobre a Terra. Apesar da abundância, o país apresenta áreas de conflito 
hídrico, dentre outras questões, devido à demanda para irrigação de arroz e da degradação da qualidade da água, principalmente em áreas de pastagens (LEAL; VICÁRIA, 2007). A Política Nacional de Recursos Hídricos (Lei no 9433, de 08 de janeiro de 1997) do país determina a água como bem de valor econômico, o que é relevante em função da abundância e importância deste recurso brasileiro.

Muitos outros fatores contribuem para a preocupante diminuição do volume de água potável, tais como: desnecessário desperdício de água, superpopulação, desmatamento, poluição e falta de conscientização da população. Apesar da má utilização do recurso, o maior desperdício não ocorre nas residências e sim nas indústrias e atividades agrícolas, que são as grandes responsáveis pelo comprometimento da qualidade e uso acelerado da água (SILVA et al., 2005).

A água não é um fator comum a se considerar, não pode ser de apropriação de poucos ou precificado e utilizado como vantagem competitiva sem que sejam considerados o bem-estar da sociedade e a segurança das nações. Além disso, esse recurso natural possui características peculiares que a tornam um bem único de precificação complexa (SAVENIJE, 2002). O mesmo autor salienta a dificuldade de se considerar todos os fatores relativos a esta questão (Figura 1). 


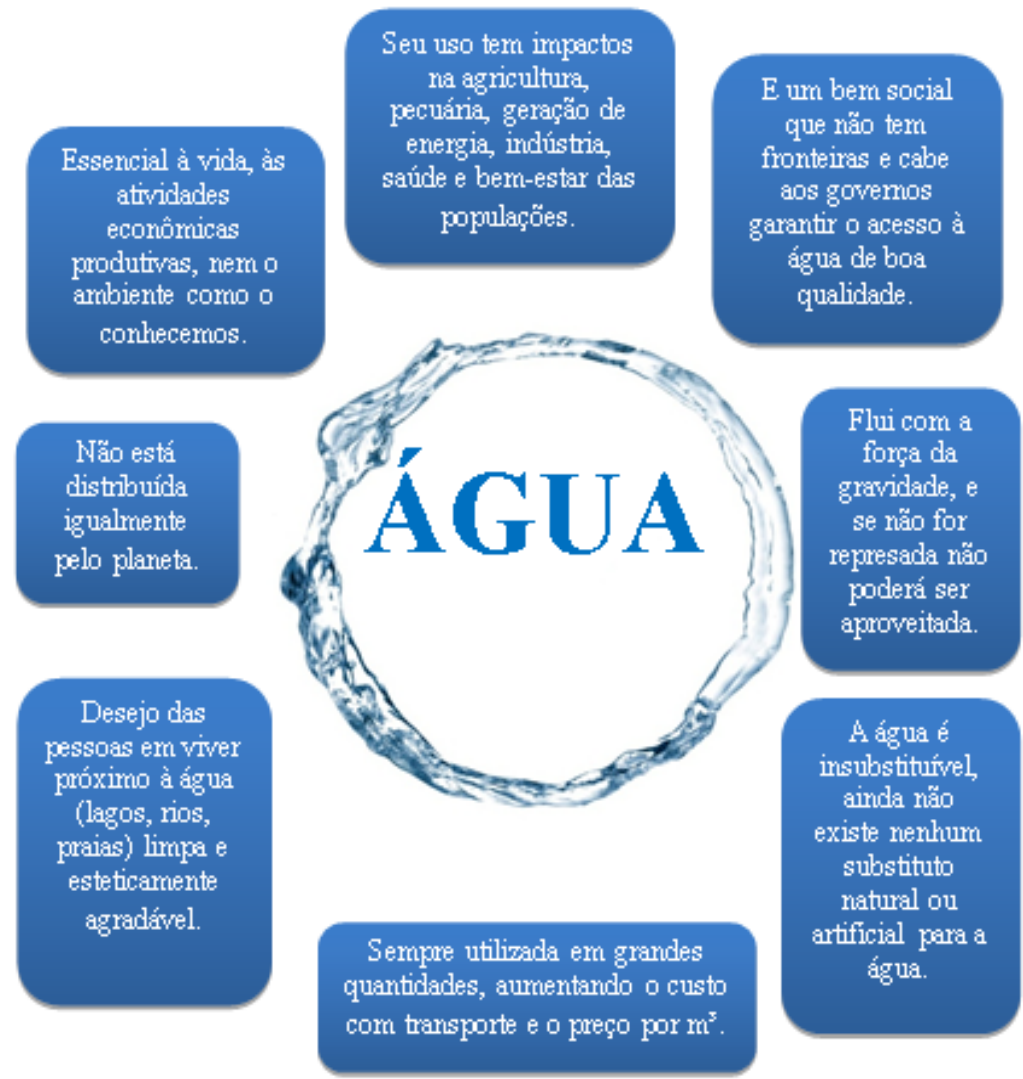

Figura 1. Características da água que interferem na determinação de seu valor. Fonte: Elaborado pelos autores conforme informações de Savenije (2002).

O conjunto desses fatores desafia pesquisadores a indicar o valor da água e como considerá-la um bem econômico, o que pode ser insuperável, pois as características da água como bem econômico e bem social podem ser incompatíveis (GLEICK et al., 2002). Em função dessas características e para seu melhor entendimento a água normalmente é dividida em azul, verde e cinza (Figura 2). 


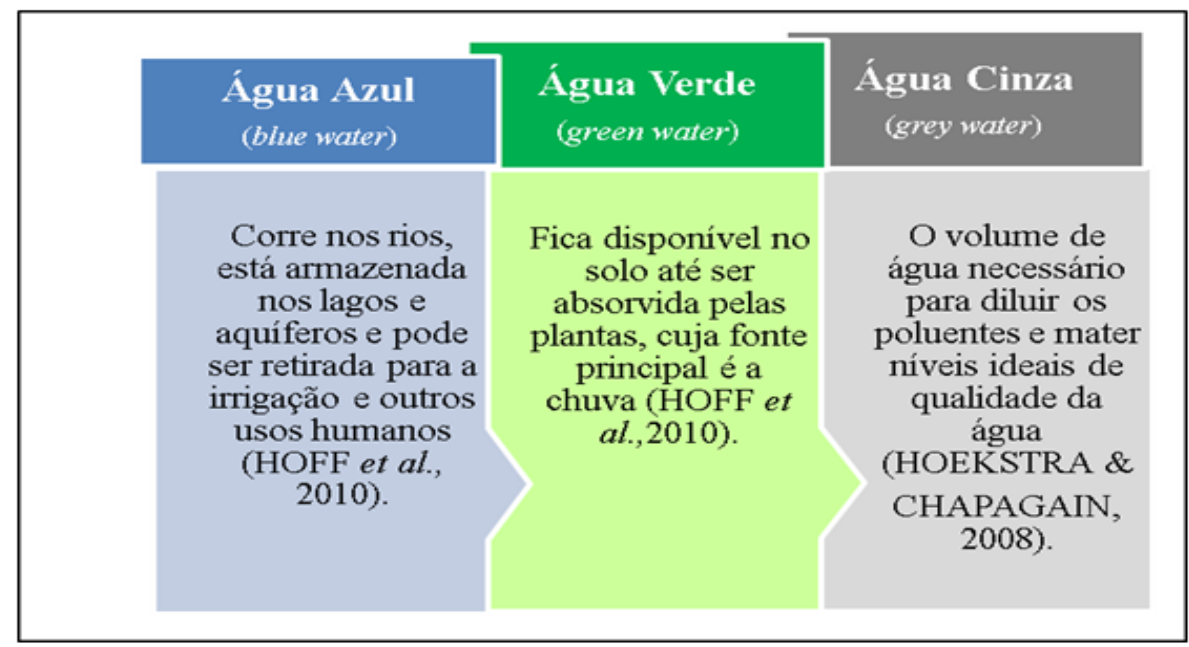

Figura 2. Caracterização da água conforme sua localização, origem, características e consumo.

Ao considerar a água como commodity (desde 1992), isto é, uma mercadoria como madeira e petróleo, começaram a surgir alertas para a possível elevação no custo desse produto (VAITSMAN; VAITSMAN, 2005). Além disso, e das questões geográficas, a disseminação da cultura irrigada e o crescimento da classe média que busca maiores confortos que geram maior consumo de água diminuem a capacidade hídrica dos países (ÁGUA \& VIDA, 2007). Esta diminuição e aumento da demanda geram conflitos sobre o compartilhamento da água, principalmente em países em que este recurso encontra-se mais escasso como Índia, Paquistão e China, potencializando o agravamento dos conflitos entre as nações.

\section{CONSUMO DA ÁGUA}

Água é um recurso que atende a sociedade em diversas instâncias. Dentre eles, pode-se citar os consumos diretos pela população, utilização na limpeza e higienização, geração de energia e o consumo indireto nos produtos.

No entanto, o consumo doméstico brasileiro apenas é valorizado no pagamento da distribuição e do tratamento que a água recebe, sem a valorização do produto em si. Entretanto, o consumo doméstico corresponde a apenas $6 \%$ do 
total (BARROS, 2005). Quanto ao consumo pelo restante dos agentes (indústria e produção agrícola), estatisticamente, a irrigação corresponde a $73 \%$ do consumo de água, 21\% vão para a indústria (BARROS, 2005).

\subsection{UTILIZAÇÃO INDIRETA DOS RECURSOS HÍDRICOS NOS CENTROS URBANOS}

Em atividades como higiene, limpeza e manutenção de uma casa são utilizados entre 50 e 200 litros de água, por dia, dependendo da localidade (FRAITURE et al., 2004). No Brasil, o consumo varia de 10 litros (em regiões áridas) a 200 litros (em regiões mais economicamente ativas como o Sudeste) (CARMO; DAGNINO; JOHANSE, 2014). Além disso, o setor de saneamento brasileiro apresenta perdas de faturamento da ordem de 40\% (COÊLHO, 2001), destacando potencial para otimização dos recursos a serem investidos, pois uma ação efetiva no desempenho organizacional pode obter retornos pelo aumento de eficiência nesses processos.

Outra questão saliente é a necessidade antropológica de recursos hídricos para os processos industriais, como fabricação de papel, extração de cana-de-açúcar, resfriamento de motores e geração de pressão de vapor (BEGOSSI, 1997).

\subsection{GERAÇÃO DE ENERGIA - HIDROELÉTRICA}

Segundo o Relatório Nacional Sobre o Gerenciamento de Água no Brasil (TUCCI et al., 2000), a geração de energia hídrica representa cerca de $91 \%$ do total da energia gerada no país, fazendo com que o Brasil dependa estrategicamente de um bom gerenciamento desse recurso. Apesar de ser considerada como energia limpa, sua instalação projeta danos ao ambiente em que se localiza e altera a estrutura ambiental e social da região.

\section{3 ÁGUA NA PRODUÇÃO DE ALIMENTOS}

Apesar das outras formas de consumo serem obviamente importantes, o setor agropecuário é o maior consumidor hídrico, podendo representar até $90 \%$ da composição física das plantas (BARROS, 2005). Nos alimentos, desapercebidamente, são consumidos milhares de litros de água diariamente, dependendo da dieta.

Maior consumidor de água azul, o setor agrícola representa cerca de 70\% de 
seu uso total (PIMENTEL, 2004). Outra questão destacada pelo autor é que o volume de água gasto em alguns produtos é muito elevado e existe a possibilidade de diminuição significativa da demanda hídrica a partir de modificações na dieta alimentar de várias populações. Nesta questão, a carne é um dos principais consumidores de água, considerando os rebanhos alimentados com ração, principalmente baseada em grãos, que são grandes demandantes de água (PIMENTEL, 2004).

A irrigação no Brasil tem passado por várias fases de investimento de acordo com as características dos empreendimentos. Nas regiões Sul e Sudeste predominam as irrigações privadas com ênfase no arroz irrigado em que o investimento depende, principalmente, do mercado do produto. No Nordeste do Brasil existe maior investimento em empreendimentos públicos, visando o desenvolvimento regional e a sustentabilidade em uma região de grande demanda. Os pontos de maior conflito são o desperdício e a baixa preocupação com a qualidade da água (TELLES, 1999).

Cerca de 30\% do espaço de água está relacionado a produtos de origem animal (MEKONNEN; HOEKSTRA, 2011). A alimentação dos animais responde por $98 \%$ da pegada de água destes produtos, sendo um destes fatores relativos à conversão alimentar que mede a quantidade de ração para produzir certa quantidade de carne, ovos ou leite. A movimentação dos animais prolonga o tempo necessário para atingir o peso de abate em sistemas de pastagem, consumindo mais alimentos e, consequentemente, mais água. Por outro lado, sistemas mistos ou exclusivamente de alimentação com grãos, que teoricamente não permitem sua locomoção, apresentam altíssima demanda hídrica relacionada à produção de grãos (GERBENS-LEENES; MEKONNEN; HOEKSTRA, 2011). Além disso, a água utilizada neste setor não retorna às suas fontes de origem ou retorna comprometida por dejetos (TELLES, 1999).

\section{VALOR DA ÁGUA CONSUMIDA POR PAÍS}

A abundância de recursos hídricos de determinada nação nunca irá suprir a demanda internacional (WICHELNS, 2004). Se a produção mundial passar a seguir uma divisão entre nações abundantes e nações de escassez de água pode inviabilizar a segurança hídrica global.

Muitos países, como Inglaterra, França e Chile, tentam solucionar o 
gerenciamento da água via concessionárias privadas, estando quase todo o negócio mundial de gestão de água nas mãos de duas empresas francesas (BARLOW; CLARKE, 2003). No Chile, a privatização da água foi implantada conforme os princípios do Banco Mundial, pois a legislação chilena é liberal em relação à água: qualquer pessoa pode requerer ao Poder Público a concessão de direito de uso da água e, se houver disponibilidade de outorga, essa não poderá ser negada. O direito de uso é um bem real do concessionário, podendo ser transmitido livremente. Esta condição gerou uma nova forma de especulação, pois certas firmas mineradoras controlam o mercado de água no país e simulam situações de falta de água com o objetivo de aumentar os preços ou criar reservas de direitos para usos futuros (IRIGARAY, 2004).

Nos países pobres, onde os serviços de água foram privatizados, aumentaram as tarifas de água. Em Gana, as condições impostas pelo Banco Mundial e o FMI determinaram um aumento de 95\% nas tarifas de água. Em Cochabamba (Bolívia), as tarifas ascenderam consumindo $25 \%$ da receita familiar de certos residentes empobrecidos, à semelhança da Índia. Na Califórnia, o comércio do direito à água já é um grande negócio, visto que, em 1992, o Congresso Norte-Americano votou um projeto de lei que permite aos agricultores venderem seus direitos de água para as cidades. Em 1997, foi cogitada a ideia de abrir um mercado de água entre os usuários do rio Colorado, possibilitando a venda de água para os Estados do Arizona, Nevada e Califórnia (BARLOW; CLARKE, 2003).

Entretanto, para estruturar a precificação da água é preciso estabelecer um entendimento mundial que cubra o custo total do uso da água, incluindo custos de investimentos, operacionais e de manutenção, além de uma taxa de escassez e de custo dos aspectos negativos do uso da água (HOEKSTRA, 2006).

\subsection{PEGADA HÍDRICA}

A Pegada Ecológica (Footprint) é um indicador territorial relativamente recente (REES, 1992; WACKERNAGEL; REES, 1996) para medir a demanda por esse recurso natural das atividades antropológicas. Este conceito comporta-se como uma câmera fotográfica documentando as demandas de recursos e assimilando os resíduos, diretos e indiretos, para manter o estilo de vida de certa população 
ou sustentar uma economia/processo de produção. Sua utilização é associada à sustentabilidade de padrões de consumo individuais (WACKERNAGEL et al., 2002), tem sido comparado com indicadores econômicos (JORGENSON; BURNS, 2007) e com a contabilidade ambiental.

Este conceito foi introduzido a fim de ter um indicador de consumo baseado no uso da água, capaz de fornecer informações úteis, além dos tradicionais índices de produção baseados nos indicadores de utilização da água (HOEKSTRA; HUNG, 2002). Seu desenvolvimento foi análogo ao conceito de pegada ecológica, introduzido nos anos 90 (REES, 1992; WACKERNAGEL; REES, 1996; WACKERNAGEL et al., 1997). A pegada hídrica é um indicador baseado no consumo do uso da água que percebe tanto utilizações diretas quanto indiretas de água de um consumidor ou produtor (HOEKSTRA; CHAPAGAIN, 2007; 2008).

\section{5 ÁGUA VIRTUAL}

Ao estudar a disponibilidade e o uso da água no planeta, foi criado o conceito de embeded water (água embutida) ao se referir à quantidade de água necessária para a produção de uma commodity (ALLAN, 1998). O mesmo autor considerou que o termo não refletia o impacto que ele desejava e publicou no mesmo ano o livro Virtual Water: a strategic resource, global solutions to regional deficits, no qual apresentou ao mundo o termo água virtual que foi imediatamente aceito e adotado por especialistas. Este conceito facilita o estabelecimento do vínculo entre água, alimentos e comércio e está intimamente relacionado ao conceito de pegada hídrica (Figura 3). 


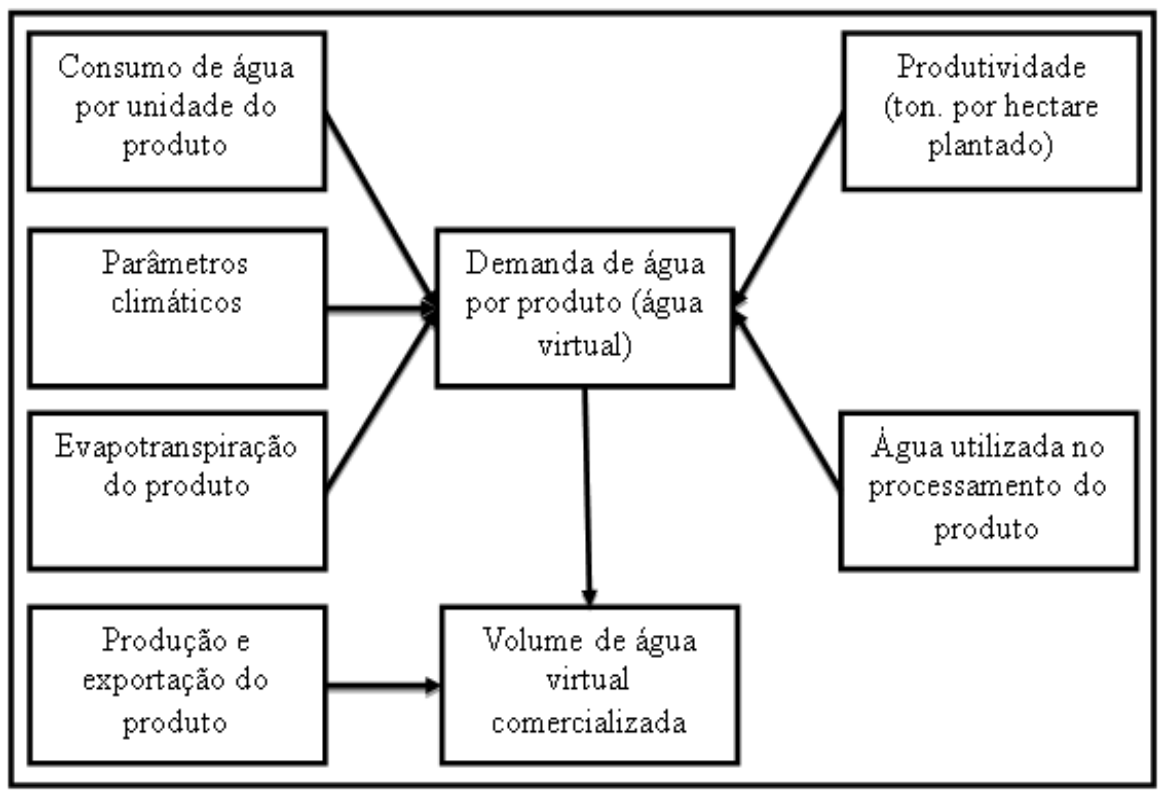

Figura 3. Esquema conceitual dos passos para as estimativas de comércio internacional de água virtual.

Fonte: Adaptado de Hoekstra e Hung (2002).

Como a maioria dos países exportadores de produtos alimentícios não utiliza a irrigação em grande escala (YANG et al., 2006), que utiliza tanto água verde como água azul, o comércio global de água virtual é dominado pela água verde, o que representa uma grande eficiência em termos de aproveitamento de um recurso de baixo custo. Neste caso pode-se citar a produção de cana-de-açúcar e soja no Brasil, que tem um alto volume de exportação dessas commodities (Tabela 1).

Tabela 1. Exportação de água virtual (em bilhões de m³), Brasil (1997-2005)

\begin{tabular}{ccccccccccc}
\hline \multirow{2}{*}{ Produto } & \multicolumn{10}{c}{ Ano } \\
\cline { 2 - 12 } & $\mathbf{1 9 9 7}$ & $\mathbf{1 9 9 8}$ & $\mathbf{1 9 9 9}$ & $\mathbf{2 0 0 0}$ & $\mathbf{2 0 0 1}$ & $\mathbf{2 0 0 2}$ & $\mathbf{2 0 0 3}$ & $\mathbf{2 0 0 4}$ & $\mathbf{2 0 0 5}$ & Total \\
\hline Soja & 18,7 & 20,8 & 20 & 25,8 & 35,2 & 35,8 & 44,6 & 43,2 & 50,3 & 294,6 \\
Carne & 7,6 & 8,9 & 10,3 & 11,5 & 17,1 & 14,7 & 19,2 & 28,6 & 34 & 151,9 \\
Açúcar & 0,8 & 1,0 & 1,6 & 0,9 & 1,5 & 1,6 & 1,7 & 2,0 & 2,4 & 13,6 \\
Total & $\mathbf{2 7 , 1}$ & $\mathbf{3 0 , 8}$ & $\mathbf{3 2 , 0}$ & $\mathbf{3 8 , 2}$ & $\mathbf{5 3 , 7}$ & $\mathbf{5 2 , 2}$ & $\mathbf{6 5 , 5}$ & $\mathbf{7 3 , 8}$ & $\mathbf{8 6 , 8}$ & $\mathbf{4 6 0 , 1}$ \\
\hline
\end{tabular}

Fonte: Carmo et al. (2007). 
Dentre as consequências mais relevantes em relação ao comércio de água virtual em países áridos e semiáridos, como a Espanha, uma delas é a mudança do paradigma de segurança da água e da segurança alimentar (FOOD ETHICS, 2008).

\subsection{COMERCIALIZAÇÃO DA ÁGUA}

De acordo com os relatórios da Conferência Internacional sobre Água e Meio Ambiente (ICWE, 1992) o conceito de água como bem econômico, ou commodity, surgiu durante as reuniões preparatórias para a ECO-92. Existem dois posicionamentos referentes a esta determinação da água como bem econômico (SAVENIJE, 2002). A primeira afirma que a água deveria ser precificada, pois tem valor econômico de forma que o mercado asseguraria o melhor uso desse recurso, visão defendida pelo Banco Mundial. Por outro lado, esta determinação envolve um processo integrado de tomada de decisões sobre a alocação desse recurso escasso, o que não implica necessariamente em uma transação financeira (MCNEILL, 1998), trazendo a questão dos princípios sociais, ambientais e éticos além de econômicos (SAVENIJE, 2002).

\subsection{COMERCIALIZAÇÃO DE ÁGUA VIRTUAL}

O fluxo mundial de água virtual divide o globo em países exportadores e importadores. Alguns países e regiões assumem uma função central nessa balança e se destacam por sua posição de exportadores. São eles: Brasil, América do Norte, América Central e também o Sudoeste Asiático (HOEKSTRA; HUNG, 2002). A Índia é considerada o quinto maior exportador de água virtual do mundo, grande parte em função da exportação expressiva de produtos vegetais (AGRAWAL; AGRAWA, 2011). O Brasil figura como um importante ponto de discussão ao se considerar a exportação de água virtual por sua importância como produtor e exportador (Tabela 1).

Como importadores, destacam-se os continentes europeu e africano, Oriente Médio e grande parte do continente asiático. Os fluxos entre importadores e exportadores ocorrem da seguinte forma: o Brasil tem como maior mercado a Europa e a Ásia (especialmente China); a América do Norte tem Europa, Ásia, África 
e também uma parcela da América Central. Ainda como exportadores, mas com fluxos menores, estão a América Latina, com seu mercado na região central e sul da Ásia, e o sudoeste asiático, também como exportador para regiões da própria Ásia (especialmente a área central e sul) (Tabela 2).

Tabela 2. Cinco maiores países exportadores e importadores de água

\begin{tabular}{|c|c|c|}
\hline Colocação & País & $\begin{array}{l}\text { Volume líquido de exportação / importação } \\
\text { (Bilhões m³ }\end{array}$ \\
\hline \multicolumn{3}{|c|}{ Países Exportadores } \\
\hline 1 & Estados Unidos & 758.3 \\
\hline 2 & Canadá & 272.5 \\
\hline 3 & Tailândia & 233.3 \\
\hline 4 & Argentina & 226.3 \\
\hline 5 & Índia & 161.1 \\
\hline \multicolumn{3}{|c|}{ Países Importadores } \\
\hline 1 & Sri Lanka & 428.5 \\
\hline 2 & Japão & 297.4 \\
\hline 3 & Holanda & 147.7 \\
\hline 4 & Coreia do Sul & 112.6 \\
\hline 5 & China & 101.9 \\
\hline
\end{tabular}

Fonte: Elaborado pelos autores e adaptado de Hoekstra e Hung (2002).

\subsection{CONSUMO DE ÁGUA COMERCIALIZADA VS CONSUMO DE ÁGUA POTÁVEL}

O consumo de água da torneira vem diminuindo e dando lugar à água engarrafada, principalmente em função da desconfiança no Brasil da procedência dessa água (REVISTA ÁGUA \& VIDA, 2009). Este aumento do consumo de água engarrafada fez com que este consumo se tornasse o quinto maior entre as bebidas, ficando atrás de refrigerantes, leite, cerveja e café solúvel e à frente de sucos (AHMAD; BAJAHLAN, 2009; VAITSMAN; VAITSMAN, 2005). Em âmbito mundial, o consumo de água mineral superou, em 2007, o volume consumido de refrigerante. Em 2008, 
o volume foi superior a 210 bilhões de litros consumidos, o que corresponde em termos monetários mais de US\$100 bilhões (REVISTA ÁGUA \& VIDA, 2009).

No Brasil, de acordo com dados do IBGE (Instituto Brasileiro de Geografia e Estatística), por meio da pesquisa de orçamentos familiares (POF), foi constatado que o consumo de água mineral saltou nos últimos 30 anos de $0,3 \mathrm{~kg}$ para 18,5 $\mathrm{kg}$ per capita por ano, sendo o produto que apresentou maior crescimento de consumo em 2002.

\section{CONSIDERAÇÕES FINAIS}

Em todos os produtos comercializados, desde alimentos e peças de vestuário até aparelhos eletrônicos, existe um consumo de água que muitas vezes está escondido e pode não aparecer em sua embalagem, aparência ou conteúdo. Assim, essa porção de água escondida, ou água virtual, muitas vezes empregada em um volume bem maior do que o esperado, também deve ser considerada na escolha dos consumidores ditos conscientes por seus produtos de consumo.

Aágua virtual é uma ferramenta eficaz para solucionar o problema de escassez de água em diferentes regiões do mundo por meio do comércio internacional. $\mathrm{O}$ conceito de água virtual para cada país é fundamental quando se pensa na tomada de decisões. A preocupação em calcular a pegada de água se deve ao fato desse recurso natural ser finito, sendo praticamente a mesma desde sua origem.

Pode-se dizer que a água disponível hoje no planeta Terra é a mesma da era pré-histórica, pois há o ciclo da água. Assim, a questão da água atualmente não é que ela esteja acabando, mas está havendo uma redução da disponibilidade de água utilizável para uma população humana crescente e considerável inexistência de gestão adequada dos recursos hídricos. Caso não sejam aprofundadas as discussões aqui tratadas, pode não ser possível manter as condições de bem-estar e segurança que a sociedade tem almejado. 


\section{REFERÊENCIAS}

AGRAWAL, T.; AGRAWA, M. M. Evaluation of water footprint and water poverty index for virtual water trading: a tool for poverty eradication through sustainable development. In: CONFERENCE ON INCLUSIVE \& SUSTAINABLE GROWTH, 2011. Proceedings... [s.l.]: Role of Industry, Government and Society, 2011.

AHMAD, M.; BAJAHLAN, A. Quality comparison of tap water vs. bottled water in the industrial city of Yanbu (Saudi Arabia). Environmental Monitoring and Assessment, v. 159, n. 1-4, p. 1-14, 2009.

ALLAN, J. A. Virtual water: a strategic resource: global solutions to regional deficits. Groundwater, v. 36, n. 4, p. 545-546, 1998.

BARLOW, M.; CLARKE, T. Blue Gold: The Battle against Corporate Theft of the World's Water. London: Earthscan, 2003.

BARROS, W. P. A água na visão do Direito. Porto Alegre: Tribunal de Justiça do Rio Grande do Sul, 2005.

BEGOSSI, A. Escalas, economia ecológica e a conservação da biodiversidade. In: CALVALCANTI, C. Meio ambiente, desenvolvimento sustentável e políticas públicas. São Paulo: Cortez, 1997.

CARMO, R. L.; DAGNINO, R. S.; JOHANSEN, I I C. Transição demográfica e transição do consumo urbano de água no Brasil. Revista Brasileira de Estudos de População, v. 31, n. 1, p. 169-190, 2014.

CARMO, R. L.; OJIMA, A. L. R.; OJIMA, R.; NASCIMENTO, T. T. do. Água virtual, escassez e gestão: o Brasil como grande "exportador" de água virtual. Ambiente e Sociedade, v. 10, n. 1, p. 83-96, 2007.

COÊLHO, A. C. Manual de economia de água: conservação de água. Olinda: Ed. Autor, 2001.

FOOD ETHICS. Food Ethics Magazine. Spring 08: Water. Food Ethics Council. 2008. Disponível em: < http://www.foodethicscouncil.org/node/343>. Acesso em: 01 ago. 2014. 
FRAITURE, C.; CAI, X.; AMARASINGHE, U.; ROSEGRANT, M.; MOLDEN, D. Does International cereal trade save water? The impact of virtual water trade on global water use. Comprehensive Assessment Research Report 4, IWMI, Colombo, 2004.

GERBENS-LEENES, P. W.; MEKONNEN, M. M.; HOEKSTRA, A. Y. A comparative study on the water footprint of poultry, pork and beef in different countries and production systems. Value of Water Res. Rep. Ser. n. 55. UNESCO-IHE, Delft, the Netherlands, 2011.

GLEICK, P. H.; WOLFF, G.; CHALECKI, E. L.; REYES, R. The new economy of water: the risks and benefits of globalization and privatization of fresh water. Pacific Institute Oakland, Ca, USA, 2002.

HESPANHOL, I.; MIERZWA, J. C. Programa para o gerenciamento de águas e efluentes nas indústrias visando o uso racional e o reuso. Engenharia Sanitária e Ambiental, v. 4, n. 11-15, 2000.

HOEKSTRA, A. Y.; CHAPAGAIN, A. K. Water footprints of nations: water use by people as a function of their consumption pattern. Water Resour Manag, v. 21, p. 35-48, 2007.

HOEKSTRA, A. Y.; CHAPAGAIN, A. K. Globalization of water: sharing the planet's freshwater re-sources. Blackwell: Oxford, 2008.

HOEKSTRA, A. Y.; HUNG, P. Q. A quantification of Virtual Water Flows between Nations in relation to International Crop Trade. Research Report Series n. 11, 2002 .

HOEKSTRA, A. Y. The global dimension of water governance: nine reasons for global arrangements in order to cope with local water problems, UNESCO - IHE, Value of Water Research Report Series, Delft, The Netherlands, n. 20, 2006.

INSTITUTO BRASILEIRO DE GEOGRAFIA E ESTATÍSTICA - IBGE. Disponível em: $<$ http://www.ibge.gov.br/home/presidencia/noticias/19052004pof2002html. shtm > . Acesso em: 01 ago. 2014.

INTERNATIONAL CONFERENCE ON WATER AND THE ENVIRONMENT - ICWE. The Dublin Statement and Report of the ICWE: development issues for the 21st century. Dublin, [s.n.], 1992. p. 26-31, 
IRIGARAY, C. T. J. H. Água: um direito fundamental ou uma mercadoria? In: CONGRESSO INTERNACIONAL DE DIREITO AMBIENTAL, 7., 2003, São Paulo. Direito Água e Vida. São Paulo, 2003. v. 1, p. 308-400.

INTERNATIONAL WATER MANAGEMENT INSTITUTE - IWMI. Challenges in developing countries: lessons from India and Elsewhere. Water Policy Briefing, $n$. 24. Colombo, IWMI, 2007.

JORGENSON, A. K.; BURNS, T. The political-economic causes of change in the ecological footprints of nations, 1991-2001: a quantitative investigation. Social Science Research. v. 36, p. 834-53, 2007.

LEAL, R.; VICÁRIA, L. Vai faltar água? por que o Brasil precisa acordar para a crise hídrica mundial antes que seja tarde. Revista Época, n. 478, p. 109-117, 2007.

McNEILL, D. Water as an economic good. Natural Resources Forum. v. 22, n. 4, p. 253-261, 1998.

MEKONNEN, M. M.; HOEKSTRA, A. Y. National water footprint accounts: the green, blue and gray water footprint of production and consumption. Value of Water Research Report Series, n. 50, 2011.

PIMENTEL, D. et al. Water Resources: Agricultural and Environmental Issues. Bioscience, v. 54, n. 10, p. 909-918, 2004.

REES, W. E. Ecological footprints and appropriated carrying capacity: what urban economics leaves out. Environ Urban. v. 4, n. 2, p. 121-130, 1992.

REVISTA ÁGUA \& VIDA. 20\% dos brasileiros não dispõem de água potável, afirma ONG. São Paulo, v. 10, n. 47, 2007.

REVISTA ÁGUA \& VIDA. Água Bonafont chega discretamente ao mercado, mas promete expansão. São Paulo, ano 12, n. 55, 2009.

SAVENIJE, H. H. G. The role of green water in food production in sub-Saharan Africa. FAO online document. 2002. Disponível em: < http://www.fao.org/nr/aboutnr/nrl/ en/> . Acesso em: 01 ago. 2014. 
SILVA, A. C. F.; BONIS, D.; BENETTI, M. P.; OLIVEIRA, R. A.; MORAES, T. G. Projeto integral, curso de comunicação social com habilitação em publicidade e propaganda. São Paulo: Centro Universitário Nove de Julho, 2005.

TELLES, D. D’A. Água na agricultura e pecuária. In: REBOUÇAS, A.; BRAGA, B.; TUNDISI, J. G. (Org.). Águas doces no Brasil: capital ecológico, uso e conservação. 2. ed. São Paulo: Escrituras, 1999. 703p.

TUCCI, C. E. M. Modelos hidrológicos. Porto Alegre: Ed. da UFRGS, 2000.

ORGANIZAÇÃO DAS NAÇÕES UNIDAS - ONU. Critical trends, global change and sustainable development. New York: USA, 1997.

VAITSMAN, D. S.; VAITSMAN, M. S. Água mineral. São Paulo: Interciência, 2005.

WACKERNAGEL, M.; REES, W. E. Our ecological footprint: reducing human impact on the earth. Gabriola Island, BC: New Society Publishers, 1996.

WACKERNAGEL, M. et al. Tracking the ecological overshoot of the human economy. Proc. Natl. Acad. Sci., v. 99, n. 14, p. 9266-9271, 2002.

WICHELNS, D. The policy relevance of virtual water can be enhanced by considering comparative advantages. Agricultural Water Management, v. 66, n. 1, p. 49-64, 2004 .

YANG, H. et al. Virtual water trade: an assessment of water use efficiency in the International food trade. Hydrology and Earth Systems Sciences, v. 10, p. 443454, 2006.

Recebido em: 01 de agosto de 2014 Revisado em: 22 de dezembro de 2015 Aceito em: 26 de dezembro de 2015 